\title{
A Novel Scale for Assessing the Burden of Caregiving for Functionally Compromised Patients: Proposal and Validation
}

\author{
Arun-Kumar Kaliya-Perumal' ${ }^{1}$, Anupama Korlakunta ${ }^{2, *}$, Jacquilyne Kharlukhi ${ }^{3}$, Sarada Devireddy ${ }^{4}$ \\ 'Department of Orthopaedic Surgery, Melmaruvathur Adhiparasakthi Institute of Medical Sciences and Research, Melmaruvathur, India \\ ${ }^{2}$ Department of Psychiatry, Kamineni Institute of Medical Sciences, Narketpally, India \\ ${ }^{3}$ Department of Paediatrics, Sri Ramachandra Medical College and Research Institute, Chennai, India \\ ${ }^{4}$ Department of Home Science, Sri Padmavati Mahila Visvavidyalayam, Tirupati, India
}

Background: Disability not only burdens the patient, but also the caregiver. To quantify this caregiving burden, we propose a simple four-part questionnaire tool. Our objective is to validate this questionnaire by administering it to caregivers who oversee patients with low back pain and are functionally compromised.

Methods: Twenty-five spouse caregivers who were taking care of in-patients awaiting surgery for various lumbar spine pathologies were shortlisted. The content-validated questionnaire was administered on different occasions during the care recipient's treatment. Cronbach's $\alpha$ was calculated to assess internal consistency. Interrelationships between the care recipient's pain score, extent of functional compromise, and caregiver burden were calculated. The questionnaire's ability to track changes in the caregivers' attitudes over time was assessed.

Results: The percentage of caregiver burden before the surgery of the care recipient was 52.5 . This increased significantly to $61.1 \%(\mathrm{P}=0.001) 3$ days after surgery, but was found to decrease to $32.5 \%(\mathrm{P}<0.001)$ a month after the surgery; demonstrating the questionnaire's efficacy to track changes. Cronbach's alpha of 0.948 signifies the questionnaire's excellent internal consistency. Pearson's correlation coefficient $(\mathrm{r})$ between the care recipient's pain score and caregiver's burden score was $0.41(\mathrm{P}=0.04)$, and between the care recipient's disability score and caregiver's burden score was $0.9(\mathrm{P}<0.001)$.

Conclusion: The proposed questionnaire is consistent and can track changes in a caregiver's attitude over time. It can be adopted for clinical use to assess the burden of caregiving for functionally compromised patients.

Keywords: Caregivers; Cost of Illness; Dependency; Disability Evaluation; Surveys and Questionnaires

Received: June 26, 2019, Revised: July 15, 2019, Accepted: July 16, 2019

*Corresponding Author: Anupama Korlakunta https://orcid.org/0000-0002-4757-5819

Tel: +91-08682-279999, Fax: +91-8682-272829, E-mail: drspinearun@gmail.com 


\section{INTRODUCTION}

Back pain has become a leading cause of disability, with a significant number of patients requiring surgery. ${ }^{1)}$ After such surgeries, returning to normalcy depends on the patient's tolerance to rehabilitation protocols. Therefore, the time required for full functional recovery may vary, and in some, cases be prolonged. ${ }^{2,3)}$ We believe that the extent of a patient's functional compromise is directly proportional to the subjective burden of family caregivers. ${ }^{4}$ Such burden depends on the condition for which the surgery is being planned, its severity, chronicity and the type of surgery. When the patient is functionally compromised, the family is subjected to physical, psychological, social, and financial burdens. ${ }^{5,6)}$ Assessing and framing measures to reduce such burden is highly essential to avoid the negative effects of caregiving.

Most of the questionnaires that are used to measure the burden of caregivers are Likert scale-based, where respondents are given a statement and are asked to rate on a scale their agreement or disagreement. ${ }^{7-9)}$ This method can be quick and efficient; however, the difference between each degree of agreement or disagreement may not be the same for every respondent. There is a chance that the actual disposition of the respondent is not reflected in their response. Moreover, it is difficult to avoid the rating of one question to be influenced by the rating of other questions or the overall rating. To reduce this bias, we formulated a 4-part questionnaire (physical, psychological, social, and financial burden) with components under each part. Each component had six statements arranged in order of ascending severity and respondents were asked to choose a statement that closely resembled their situation. We intended to validate our questionnaire tool by prospectively implementing it in our clinical setting to assess the burden among caregivers who were taking care of functionally compromised patients with low back pain undergoing spine surgery. We also intended to check the interrelationship between the care recipient's pain score, degree of functionality compromised, and the caregiver's burden.

\section{METHODS}

We short-listed spouse caregivers who were taking care of in-patients scheduled for surgery for various lumbar spinal pathologies, including intervertebral disc herniations, instabilities, infections, and degenerative conditions of the lumbar spine. We only included: (1) those who did not have any assistance and were solely responsible for the caregiving situation, (2) those involved in caregiving for at least a month before the admission of the care recipient, and (3) those with no history of any kind of disabling illness affecting their own wellbeing. We excluded: (1) caregivers who had support from other family members, (2) those who provided care for shorter than a month, and (3) those with known psychiatric disorders such as stress or depression. Selected caregivers received information about the importance of the caregiver assessment which identifies specific problems and their ability to contribute to the needs of the patient.
We clearly explained to all the caregiving spouses the details of our study and obtained implied consent from both the caregiving spouse and the corresponding care recipient when they agreed to answer the questionnaire. No direct personal identifiers were collected. All of them were briefed about the questionnaire tool that we had developed for the assessment of the caregiver burden where we divided the overall caregiver burden into four divisions: physical, psychological, social, and financial (Table 1). We believe that these four divisions reflect the major difficulties faced by family caregivers who we generally encounter, especially those from a poor economic background and those who lack community or financial support in the form of governmental policies. Therefore, we wanted our questionnaire to encapsulate these issues. In the questionnaire, physical and psychological burden were each scored according to three components. Social and financial burden were each scored according to two components. For each component, the maximum score was 5 and there were six statements describing different potential scenarios.

The caregiver was asked to choose a statement for each component that closely resembled their situation. Choosing the first statement resulted in a score of 0 , while selecting the last statement resulted in a score of 5 . All four divisions and corresponding components had to be completed to obtain a score out of 50 which can then be converted to a percentage; if one component was not applicable, then the score could be calculated out of 45 .

Content validation of the questionnaire was done by expert psychiatrists. They were asked to compute the percentage of components in the questionnaire that seemed to be relevant for measuring the caregiver's burden; from this, the average congruency percentage (ACP) was calculated. In addition, we asked the expert psychiatrists to grade the relevance of each component of the questionnaire on a 4-point Likert scale ( $1=$ not relevant, $2=$ somewhat relevant, $3=$ relevant, $4=$ =ery relevant) with a score of 3 or 4 being considered as relevant. For each component, the proportion of experts giving 3 or 4 rating was noted; after which, the content validity index for individual items (I-CVI) was determined. The proportion of questions in our questionnaire that was deemed relevant by all expert psychiatrists was calculated as the content validity index for the scale (S-CVI).

Our questionnaire tool can be self-administered. However, to minimize the cognitive burden of the respondent, an interviewer, who was one of those who designed the questionnaire, administered it to the caregivers. The interviewer collected the responses of the questionnaires from all the selected caregiving spouses before the surgery of the care recipient and their percentage of burden was calculated. The internal consistency of items included in our questionnaire was assessed by calculating Cronbach's coefficient $\alpha$. In addition, we quantified the care recipient's pain using the Numeric Rating Scale (NRS) pain score and functional status using Roland Morris Disability Questionnaire score. Using this data, the linear relationships between the care recipient's pain score, disability questionnaire score, and caregiver burden score were assessed.

Since the measure of burden using our questionnaire is expected to 
Table 1. Four-part caregiver burden assessment questionnaire

\begin{tabular}{|c|c|c|}
\hline Part & Questionnaire & Score \\
\hline \multicolumn{3}{|l|}{ Part I: physical burden } \\
\hline 1 & $\begin{array}{l}\text { Personal care of the dependent (bathing, dressing, etc.) } \\
\text { - I don't have to look after the personal care of my dependent. } \\
\text { - I only supervise the personal care of my dependent. } \\
\text { - I must lend a hand to help with the personal care of my dependent. } \\
\text { - I must assist in less than } 50 \% \text { of my dependent's personal care. } \\
\text { - I must assist in more than } 50 \% \text { of my dependent's personal care. } \\
\text { - I must do all my dependent's personal care. }\end{array}$ & \\
\hline 2 & $\begin{array}{l}\text { Household work of the dependent (housekeeping, helping oneself, etc.) } \\
\text { - I don't have to do anything except my own household work. } \\
\text { - I only supervise when my dependent is doing some household work. } \\
\text { - I must lend a hand when my dependent is doing some household work. } \\
\text { - I must do less than } 50 \% \text { of my dependent's household work. } \\
\text { - I must do more than 50\% of my dependent's household work. } \\
\text { - I must do all my dependent's household work in addition to mine. }\end{array}$ & \\
\hline 3 & $\begin{array}{l}\text { My personal health } \\
\text { - My health is by no means affected because of caregiving. } \\
\text { - I am worried about my health because of caregiving. } \\
\text { - I'm ok, but I feel physically exhausted because of caregiving. } \\
\text { - I feel I will soon become ill because of caregiving. } \\
\text { - I am ill, and I feel like I need support. } \\
\text { - I am ill, and I cannot continue caregiving. }\end{array}$ & \\
\hline \multicolumn{3}{|c|}{ Overall score for physical burden } \\
\hline \multicolumn{3}{|c|}{ Part II: psychological burden } \\
\hline 4 & $\begin{array}{l}\text { Overall satisfaction of the care I provide } \\
\text { - I am extremely satisfied with the care I provide for my dependent. } \\
\text { - I think I am able to provide the basic care for my dependent. } \\
\text { - I think I need to improve with my caregiving. } \\
\text { - I feel that there is something wrong with the care I provide. } \\
\text { - I am not satisfied with the care I provide. } \\
\text { - I am fed up with this caregiving situation. }\end{array}$ & \\
\hline 5 & $\begin{array}{l}\text { Concern about my dependent's future } \\
\text { - My concern about my dependent's future is not worrisome. } \\
\text { - I worry to a small degree about my dependent's future. } \\
\text { - I am worried, but I believe everything will be alright soon. } \\
\text { - I am worried, and I believe this is going to take time. } \\
\text { - I am worried as there is only minimal improvement. } \\
\text { - I am extremely worried as there is no improvement. }\end{array}$ & \\
\hline 6 & $\begin{array}{l}\text { Concern about my own future } \\
\text { - This caregiving situation will not affect my future in any way. } \\
\text { - I am slightly worried that the present situation may have some impact on my future. } \\
\text { - I am worried about the present situation, but I believe it will be alright soon. } \\
\text { - I am worried about the present situation and I believe this is going to take time. } \\
\text { - My future is getting spoiled as I am stuck with this caregiving situation. } \\
\text { - I have no future because of this caregiving situation. }\end{array}$ & \\
\hline
\end{tabular}

Overall score for psychological burden

Part III: social burden

7

8
Relationships with other family members and friends

- My relationships are in no way affected.

- I think my relationships might get affected.

- My relationships have started to get affected.

- My relationships are affected to a small degree.

- My relationships are affected to a great degree.

- My relationships are suffering.

Social and leisure activities

- I can participate in all social and leisure activities.

- I must adjust, but can participate in all social and leisure activities.

- I can participate in most of the social and leisure activities.

- I can participate in a few of the social and leisure activities.

- I can rarely participate in social and leisure activities.

- I cannot participate in any social and leisure activities. 
Table 1. Continued

\begin{tabular}{cl}
\hline \multicolumn{1}{c}{ Part } & \multicolumn{1}{c}{ Questionnaire } \\
\hline Part IV: financial burden & Score \\
\hline 7 & Financial resources other than periodical income (savings, property, etc.) \\
& - This caregiving situation will not affect my financial resources. \\
& - I have started to spend wisely to protect my financial resources. \\
& - My financial resources have started to deplete. \\
& - Less than $50 \%$ of my financial resources have depleted. \\
& - More than $50 \%$ of my financial resources have depleted. \\
& - I am financially broken down. \\
& Periodical income \\
& - This caregiving situation will not affect my periodical income. \\
& - I might have to avail of a leave of absence without pay. \\
& - Sometimes I take a leave of absence without pay for a day or 2. \\
& - I am frequently taking a leave of absence without pay for a day or 2. \\
& - I have been on a leave of absence without pay for quite a long time now. \\
& - I lost/quit my job because of the caregiving situation.
\end{tabular}

Overall score for financial burden

Overall care giver burden score

If all 10 components of the questionnaire are applicable, then the score is calculated as follows: example: 27 (total score)/50 (total possible score) $\times 100=54 \%$. If one section is not applicable, then the score is calculated as follows: 27 (total score)/45 (total possible score) $\times 100=60 \%$.

change over time, assessing the test-retest reliability using measures at two different occasions may not be appropriate; instead, the questionnaire can be used to track changes in caregiver attitudes over time. Therefore, we calculated the percentage of burden in caregivers at 1 week, 1 month, and 3 months after the surgery of the care recipient. Statistical analyses were done to check if there were significant changes in burden measures taken at different occasions.

\section{Statistical Analysis}

Statistical analysis to measure the internal consistency of the questionnaire was done using PASW SPSS ver. 18.0 (SPSS Inc., Chicago, IL, USA). We interpreted Cronbach's coefficient $\alpha$ as excellent ( $\alpha \geq 0.9$ ), good ( $0.9>\alpha \geq 0.8)$, acceptable (0.8> $\alpha \geq 0.7)$, questionable ( $0.7>\alpha$ $\geq 0.6)$, poor $(0.6>\alpha \geq 0.5)$, and unacceptable $(\alpha<0.5)$. Correlation analyses were done using Graph Pad Prism 5 (GraphPad Software Inc., San Diego, CA, USA). We interpreted Pearson's correlation coefficient (r) as very weak $(0-0.19)$, weak $(0.20-0.39)$, moderate $(0.40-0.59)$, strong $(0.60-0.79)$, and very strong $(0.80-1.0)$. Student t-test was used to analyze the significant difference between paired observations of burden where a probability value $(\mathrm{P})$ of less than 0.05 was considered statistically significant.

\section{Ethics Approval}

This study was approved by the Sri Padmavati Mahila Visvavidyalayam ethics committee on 15/10/2018 (R.O.C. No.SPMVV/Acad/C1/2018). Informed consent was obtained from all care recipients to use their anonymised data for research. Implied consent was applicable when the caregivers choose to respond to the questionnaire. The study was performed in accordance with the ethical standards described in the latest version of the 1964 declaration of Helsinki, or comparable ethical standards.
Table 2. Characteristics of care recipients and caregivers

\begin{tabular}{lc}
\hline \multicolumn{1}{c}{ Characteristic } & Value \\
\hline Care recipients & \\
Age (y) & $42.1 \pm 6.7(31-55)$ \\
Sex (male:female) & $7: 18$ \\
Preop numeric rating scale pain score & $8.1 \pm 0.7$ \\
Preop Roland-Morris Disability Questionnaire score & $20.2 \pm 1.7$ \\
Caregivers & \\
Age (y) & $43.6 \pm 6.4(33-57)$ \\
Sex (male:female) & $18: 7$ \\
Preop \% of burden & $52.5 \pm 13.8$
\end{tabular}

Values are presented as mean \pm standard deviation (range) or number. Preop, preoperative.

\section{RESULTS}

We selected 25 spouse caregivers (age: mean \pm standard deviation [SD], $43.6 \pm 6.4$ years; range, $33-57$ years; male, 18 ; female, 7 ) of chronic low back pain patients (age: mean \pm SD, $42.1 \pm 6.7$ years; range, $31-55$ years) admitted to our orthopedic ward for at least 3 days awaiting surgery for various spinal pathologies (Table 2). Their duration of caregiving was noted and the mean ( $2.2 \pm 0.7$ months) was calculated. The ACP, I-CVI, and S-CVI of our newly formulated questionnaire were calculated by five expert psychiatrists. They graded the relevance of each component of the questionnaire on a 4-point Likert scale. All experts believed that every component of the questionnaire dealt with something that will affect the mental health of the caregiver. Four experts gave a Likert scale rating of 3 or 4 for all components. One expert gave a rating of 3 or 4 for all components except "financial resources other than periodical income," for which he gave a rating of 2. Using these ratings, ACP was calculated to be $98 \%$. Mean I-CVI was 0.98 and S-CVI universal acceptance was 0.90 (Table 3). 
Table 3. Assessment of content validity

\begin{tabular}{|c|c|c|c|c|c|c|c|}
\hline Component & Expert 1 & Expert 2 & Expert 3 & Expert 4 & Expert 5 & Congruency \% & I-CVI \\
\hline \multicolumn{8}{|l|}{ Physical burden } \\
\hline 1 & 4 & 4 & 4 & 4 & 4 & 100 & 1.0 \\
\hline 2 & 4 & 4 & 4 & 3 & 4 & 100 & 1.0 \\
\hline 3 & 4 & 4 & 4 & 4 & 4 & 100 & 1.0 \\
\hline \multicolumn{8}{|c|}{ Psychological burden } \\
\hline 4 & 3 & 3 & 3 & 4 & 4 & 100 & 1.0 \\
\hline 5 & 4 & 3 & 4 & 4 & 4 & 100 & 1.0 \\
\hline 6 & 4 & 4 & 4 & 4 & 4 & 100 & 1.0 \\
\hline \multicolumn{8}{|l|}{ Social burden } \\
\hline 7 & 4 & 4 & 4 & 4 & 4 & 100 & 1.0 \\
\hline 8 & 4 & 4 & 4 & 4 & 4 & 100 & 1.0 \\
\hline \multicolumn{8}{|l|}{ Financial burden } \\
\hline 9 & 4 & 2 & 3 & 3 & 4 & 80 & 0.8 \\
\hline 10 & 4 & 4 & 4 & 4 & 4 & 100 & 1.0 \\
\hline
\end{tabular}

Expert ratings are based on a 4-point Likert scale (1=not relevant, $2=$ somewhat relevant, $3=$ relevant, $4=$ very relevant). Average congruency percentage=98\%; mean $\mathrm{I}-\mathrm{CV} \mathrm{I}=0.98$; scale content validity index universal acceptance $=0.90$.

I-CVI, item-content validity index.

Table 4. Caregiver responses representing burden scores for each component of the questionnaire during the care recipient's preoperative period

\begin{tabular}{|c|c|c|c|c|c|c|c|c|c|c|c|}
\hline \multirow{2}{*}{$\begin{array}{l}\text { Caregiver } \\
\text { serial no. }\end{array}$} & \multicolumn{3}{|c|}{ Physical burden } & \multicolumn{3}{|c|}{ Psychological burden } & \multicolumn{2}{|c|}{ Social burden } & \multicolumn{2}{|c|}{ Financial burden } & \multirow{2}{*}{$\begin{array}{l}\text { Overall burden } \\
\text { score }\end{array}$} \\
\hline & Q1 & Q2 & Q3 & Q4 & Q5 & Q6 & Q7 & Q8 & Q9 & Q10 & \\
\hline 1 & 3 & 3 & 2 & 2 & 3 & 3 & 3 & 4 & 1 & 2 & $26 / 50$ \\
\hline 2 & 4 & 4 & 2 & 1 & 5 & 4 & 4 & 4 & 2 & 3 & $33 / 50$ \\
\hline 3 & 4 & 5 & 3 & 3 & 5 & 4 & 4 & 4 & 2 & 3 & $37 / 50$ \\
\hline 4 & 2 & 2 & 1 & 1 & 2 & 0 & 1 & 2 & 1 & 2 & $14 / 50$ \\
\hline 5 & 4 & 4 & 3 & 2 & 5 & 3 & 4 & 4 & 3 & - & $32 / 45$ \\
\hline 6 & 3 & 3 & 1 & 1 & 3 & 3 & 3 & 4 & 2 & 3 & $26 / 50$ \\
\hline 7 & 3 & 2 & 1 & 1 & 2 & 2 & 1 & 2 & 1 & 2 & $17 / 50$ \\
\hline 8 & 3 & 3 & 2 & 3 & 4 & 3 & 3 & 4 & 2 & 3 & $30 / 50$ \\
\hline 9 & 3 & 2 & 1 & 1 & 2 & 1 & 1 & 1 & 1 & 2 & $15 / 50$ \\
\hline 10 & 3 & 4 & 2 & 1 & 3 & 3 & 4 & 3 & 2 & - & $25 / 45$ \\
\hline 11 & 3 & 3 & 2 & 2 & 3 & 3 & 4 & 4 & 2 & 3 & $29 / 50$ \\
\hline 12 & 4 & 4 & 3 & 3 & 3 & 3 & 4 & 4 & 3 & 3 & $34 / 50$ \\
\hline 13 & 3 & 3 & 2 & 2 & 3 & 3 & 3 & 3 & 2 & 3 & $27 / 50$ \\
\hline 14 & 3 & 3 & 3 & 2 & 2 & 2 & 3 & 3 & 2 & 3 & $26 / 50$ \\
\hline 15 & 2 & 2 & 2 & 1 & 2 & 1 & 2 & 1 & 1 & 2 & $16 / 50$ \\
\hline 16 & 3 & 3 & 3 & 2 & 2 & 2 & 3 & 3 & 2 & 3 & $26 / 50$ \\
\hline 17 & 3 & 3 & 2 & 2 & 3 & 3 & 3 & 3 & 2 & 3 & $27 / 50$ \\
\hline 18 & 4 & 4 & 3 & 3 & 3 & 3 & 3 & 3 & 3 & 3 & $32 / 50$ \\
\hline 19 & 3 & 3 & 2 & 1 & 3 & 3 & 3 & 4 & 2 & 3 & $27 / 50$ \\
\hline 20 & 3 & 3 & 2 & 2 & 3 & 3 & 3 & 3 & 2 & 3 & $27 / 50$ \\
\hline 21 & 3 & 2 & 1 & 1 & 2 & 1 & 2 & 1 & 1 & 2 & $16 / 50$ \\
\hline 22 & 4 & 4 & 3 & 3 & 3 & 3 & 3 & 4 & 3 & 4 & $34 / 50$ \\
\hline 23 & 3 & 3 & 2 & 3 & 3 & 3 & 4 & 4 & 3 & 4 & $32 / 50$ \\
\hline 24 & 3 & 3 & 2 & 1 & 3 & 3 & 3 & 3 & 2 & 3 & $26 / 50$ \\
\hline 25 & 2 & 2 & 1 & 1 & 2 & 2 & 2 & 1 & 1 & 2 & $16 / 50$ \\
\hline
\end{tabular}

Q, questionnaire component.

This questionnaire was administered to the selected caregivers before the surgery of their corresponding care recipients and their percentage of burden $(52.5 \% \pm 13.8 \%)$ was calculated. The score of each statement on the questionnaire given by all caregivers was noted and the data was coded to analyze the internal consistency of the questionnaire (Table 4). There were two female caregivers whose responses were excluded for analyzing the overall internal consistency; this was because the periodical income component of the questionnaire was not applicable to them as they did not contribute to the family's income. Hence, there were 23 valid and two excluded sets of responses with which a Cronbach's $\alpha$ of 0.948 was achieved (Table 5). This signifies that the questionnaire has an excellent internal consistency. 
Table 5. Internal consistency of the questionnaire

\begin{tabular}{lccc}
\hline \multicolumn{1}{c}{ Analysis } & $\begin{array}{c}\text { No. of } \\
\text { components }\end{array}$ & $\begin{array}{c}\text { No. of valid } \\
\text { responses }\end{array}$ & Cronbach's $\alpha$ \\
\hline Overall & 10 & 23 & 0.948 \\
Physical burden & 3 & 25 & 0.893 \\
Psychological burden & 3 & 25 & 0.782 \\
Social burden & 2 & 25 & 0.883 \\
Financial burden & 2 & 23 & 0.948 \\
\hline
\end{tabular}

The care recipient's NRS pain score $(8.1 \pm 0.7)$ and Roland-Morris Disability Questionnaire score $(20.2 \pm 1.7)$ were noted. We found that the patient's pain score, disability score, and caregiver's burden score were interdependent; that is, the caregiver's burden increased proportionally with an increase in the pain or disability score. This inference was achieved by calculating the Pearson's correlation coefficient between: (1) care recipient's pain score and caregiver's burden score ( $\mathrm{r}=0.41, \mathrm{P}=0.04)$; (2) care recipient's disability score and caregiver's burden score $(\mathrm{r}=0.9, \mathrm{P}<0.001)$. This signifies a strong uphill positive linear relationship between the care recipient's disability score and caregiver's burden score (Figure 1).

We also found that the percentage of caregiver burden significantly increased $(61.1 \% \pm 9.3 \%) 3$ days following the surgery of the care recipient when compared to the pre-surgery status $(\mathrm{P}=0.001)$. However, the caregiver burden significantly decreased at a greater increment $(32.5 \% \pm 9.8 \%) 1$ month following the surgery of the care recipient when compared to the pre-surgery status $(\mathrm{P}<0.001)$. By 3 months, telephone interviews with all caregivers were done, and only six of the caregivers reported that they are still caregiving; this was because their care recipients were not at their full functional status. Considering the questionnaire responses of these six caregivers, the percentage of burden was $14.7 \% \pm 3 \%$ at 3 months following the surgery of their care recipients.

Our results denote that the caregiver burden varies at different points in time during the treatment of the care recipient (Figure 2). This inference shows that the questionnaire is capable of detecting change in caregiver attitudes over time. Therefore, this new caregiver burden assessment tool can be deemed useful and can be adopted to measure the subjective burden of caregivers of long-term disabled patients.

\section{DISCUSSION}

It is difficult to recognize the symptoms of stress and depression in oneself, or even to admit it; through a questionnaire, we can quantify the degree of burden felt and short-list those at risk of developing mental illness. For this reason, we wanted to formulate a caregiver burden scale that will appraise the major difficulties faced by family caregivers from a poor economic background and those without community or financial support. We emphasize that it is important to measure this caregiver burden as greater degrees of stress and depression are reported in people providing such care. ${ }^{10)}$ As understood from ex-

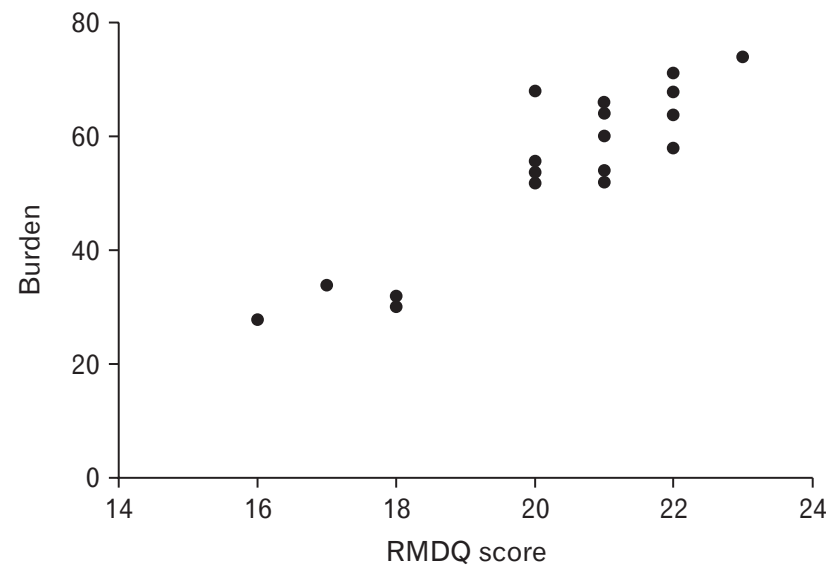

Figure 1. Linear relationship between caregiver burden and care recipient's functional score. RMDQ, Roland-Morris Disability Questionnaire.

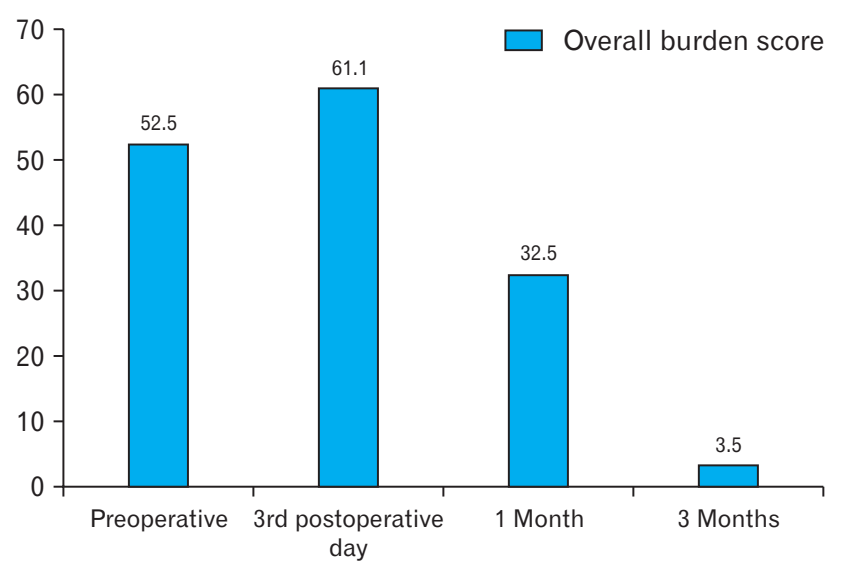

Figure 2. Variation in caregiver burden at different points in time during the treatment of the care recipient.

isting literature, the most important contributors to burden are poor physical, psychological, social, and financial wellbeing. Therefore, we wanted our scale to be inclusive of all these issues and yet be short and comprehensive.

The questionnaire was developed to be self-administered and in English for global utility. However, as most of the caregivers we interviewed do not speak English, and to reduce the cognitive burden of the responder, we followed the interviewing model. As the interviewer was one of the people who designed the questionnaire, the questions were clearly explained to the responder. We also considered that by interviewing the responder, we can identify drawbacks in the questions and rephrase them if necessary; however, this was not needed. Moreover, as all 10 items of the questionnaire were deemed relevant by expert psychiatrists, there were no attempts to further refine the questionnaire after formulation.

Early detection of caregiver burden is highly essential not only to avoid negative outcomes of the care situation, but also to prevent a more serious mental illness from manifesting. ${ }^{11)}$ Hence, early symptoms of stress and depression need to be detected and addressed with 
a healthy diet, positive support, and consultation with trained mental health professional. In the clinical scenario, the ideal person who can detect stress or depression in caregivers is the clinician who oversees the care recipient. The clinician can interview or administer the questionnaire to caregivers of patients who are frequent visitors to the outpatient clinic or to caregivers of patients hospitalized long. Based on the questionnaire's responses, if there is a suspicion that a caregiver is affected, appropriate counselling can be provided. It is understood that caregiving and the burden associated with it are unavoidable; however, if the percentage of burden remains above $50 \%$ for prolonged periods, psychologist intervention can be sought.

As inferred from our study, the more functionally compromised and pain of the care recipient, the more the caregiver burden. This inference adds to the fact that the ill effects of caregiving are always associated with the care recipient's behavioral problems, cognitive impairment, functional disabilities, and duration of care. ${ }^{12-14)}$ The major limitation of this study is a lack of comparison between the proposed scale and existing caregiver burden scales. We did not do a comparison because our primary intention was to validate this questionnaire, and to keep our assessment simple during the already burdening situation of the participants. Besides that, this measure of burden only reflects the attitude of the caregiver at a particular point of time. Moreover, various factors can influence the responses to questionnaires measuring caregiver burden, ${ }^{15)}$ such factors include income, level of education, caregiver's fatigue, cognitive abilities, assessment setting, person administering the questionnaire, and motivational factors. Hence, burden measurement is only subjective; it is essential to bring about suspicion and early detection of ill mental health.

In conclusion, the proposed four-part inventory for caregiver burden was deemed relevant by expert psychiatrists and proved to have an excellent internal consistency. By providing statements to choose from, the cognitive burden on the respondent is reduced. We have demonstrated the usefulness of this questionnaire in quantifying the subjective burden of caregivers of functionally compromised patients. By using the questionnaire, we noticed a strong correlation between the caregiver's burden and the care recipient's functional compromise. It was also possible to track changes in caregiver attitudes over time. Therefore, we believe that this questionnaire can be adopted for clinical use to assess the burden of caregivers of chronic disabled patients.

\section{CONFLICT OF INTEREST}

No potential conflict of interest relevant to this article was reported.

\section{ORCID}

Arun-Kumar Kaliya-Perumal: https://orcid.org/0000-0002-2747-4500
Anupama Korlakunta: https://orcid.org/0000-0002-4757-5819 Jacquilyne Kharlukhi: https://orcid.org/0000-0001-9243-1227 Sarada Devireddy: https://orcid.org/0000-0002-2569-928X

\section{REFERENCES}

1. Friedly J, Standaert C, Chan L. Epidemiology of spine care: the back pain dilemma. Phys Med Rehabil Clin N Am 2010;21:659-77.

2. Shifflett GD, Hellman MD, Louie PK, Mikhail C, Park KU, Phillips FM. Return to golf after lumbar fusion. Sports Health 2017;9:280-4.

3. Christman T, Li Y. Pediatric return to sports after spinal surgery. Sports Health 2016;8:331-5.

4. Garlo K, O'Leary JR, van Ness PH, Fried TR. Burden in caregivers of older adults with advanced illness. J Am Geriatr Soc 2010;58:2315-22.

5. Rofail D, Maguire L, Kissner M, Colligs A, Abetz-Webb L. A review of the social, psychological, and economic burdens experienced by people with spina bifida and their caregivers. Neurol Ther 2013;2:1-12.

6. Laskar AR, Gupta VK, Kumar D, Sharma N, Singh MM. Psychosocial effect and economic burden on parents of children with locomotor disability. Indian J Pediatr 2010;77:529-33.

7. Graessel E, Berth H, Lichte T, Grau H. Subjective caregiver burden: validity of the 10-item short version of the Burden Scale for Family Caregivers BSFC-s. BMC Geriatr 2014;14:23.

8. Konerding U, Bowen T, Forte P, Karampli E, Malmstrom T, Pavi E, et al. Investigating burden of informal caregivers in England, Finland and Greece: an analysis with the short form of the Burden Scale for Family Caregivers (BSFC-s). Aging Ment Health 2018;22:280-7.

9. Seng BK, Luo N, Ng WY, Lim J, Chionh HL, Goh J, et al. Validity and reliability of the Zarit Burden Interview in assessing caregiving burden. Ann Acad Med Singapore 2010;39:758-63.

10. Chadda RK. Caring for the family caregivers of persons with mental illness. Indian J Psychiatry 2014;56:221-7.

11. Yamagami T, Harada K, Hashidate H, Asakawa Y, Nihei K, Kaneya S, et al. Obtaining information from family caregivers is important to detect behavioral and psychological symptoms and caregiver burden in subjects with mild cognitive impairment. Dement Geriatr Cogn Dis Extra 2016;6:1-9.

12. Schulz R, Sherwood PR. Physical and mental health effects of family caregiving. Am J Nurs 2008;108(9 Suppl):23-7.

13. Yu H, Wang X, He R, Liang R, Zhou L. Measuring the caregiver burden of caring for community-residing people with Alzheimer's disease. PLoS One 2015;10:e0132168.

14. Girgis A, Lambert S, Johnson C, Waller A, Currow D. Physical, psychosocial, relationship, and economic burden of caring for people with cancer: a review. J Oncol Pract 2013;9:197-202.

15. Bowling A. Mode of questionnaire administration can have serious effects on data quality. J Public Health (Oxf) 2005;27:281-91. 